\title{
MAPAS DE MÉXICO: \\ REVISTAS DE VIAJE ILUSTRADAS DE LOS AÑOS CINCUENTA
}

\author{
POR \\ Claire Lindsay \\ University College London
}

Desde fines de los años veinte en adelante, diversas revistas surgieron dentro y fuera de México con el objetivo de promocionar al país como destino de vacaciones y atraer los dólares provenientes del turismo hacia el sur. Estas se convirtieron en un importante medio para estimular una industria transnacional de la que México comenzaba a depender, tanto para su recuperación económica y estabilidad política luego de la Revolución, como para la transformación de la nación en una república moderna. Adoptaron diversas formas: desde el folleto inaugural publicado en inglés por el Departamento de Turismo en 1929; el boletín mensual de William Furlong, The Furlong Service, en los años treinta; a los folletos producidos por la Asociación Mexicana de Turismo durante el período de la posguerra y títulos como Mexican World: Voice of Latin America y Mexican Life. Estos conjuntos de artículos, fotografías, mapas $\mathrm{y}$ anuncios publicitarios (a menudo bilingües y/o binacionales, cooperaciones públicoprivadas) simultáneamente robustecierion y mercantilizaron la cultura mexicana, sustentando y desestabilizando una floreciente mirada turística que históricamente había considerado a México como un país políticamente inestable y económica y racialmente atrasado. Este ensayo, tomando como referencia investigaciones recientes sobre la historia cultural de México que consideran al turismo "como algo más que una mera forma de imperialismo... una forma de diplomacia pública" (Berger y Wood 108), se centra en el estudio del caso de Mexico This Month, un medio fundado en la cumbre del llamado "milagro mexicano". Este ensayo, que forma parte de un proyecto más amplio que examina el modo en que las revistas visualizaron y narrativizaron al país durante las décadas en que el turismo fue clave para su modernización, responde a la invitación de Susannah Glusker a emprender "un análisis de la contribución de Mexico This Month a la promoción de México" (Glusker, Anita Brenner 15). De este modo, esta investigación aspira a contribuir a estudios recientes sobre la historia de, y la relación entre, el turismo y la producción cultural en México, como es el caso de la labor de Dina Berger, Dennis Merrill y Alex Saragoza. Su trabajo, pese a ser fundamental para mi investigación, "termina donde el éxito [turístico] empieza" (es 
decir, en 1946) y, además, omite a la revista como fuente original pertinente, ofreciendo una visión truncada del rico y diverso sistema promocional de una industria cuyos vaivenes durante la "Edad de Oro" de México también merecen atención. La revista, sostengo, es un objeto de estudio especialmente concluyente en dicho contexto, no solo debido a su incuestionable aceptación y popularidad en la región durante el período, sino también debido a su heterogeneidad y flexibilidad como medio. Este ensayo está organizado de la siguiente manera: en primer lugar, aborda el contexto en que surgió la revista, para luego dar cuenta de cómo Mexico This Month operó en términos formales como vehículo para impulsar el turismo y la economía en un período crucial para la modernización de México. La segunda parte del ensayo se enfoca específicamente en el estudio de lo que llegaría a transformarse, en los primeros años de la revista, en una serie característica de mapas desplegables. Fundamentalmente, sugeriré que Mexico This Month articuló una fantasía de capital vinculada con, pero también potencialmente desestabilizada por, una segunda y más compleja fantasía de conquista. Los mapas a los que me refiero en el título de este ensayo, por lo tanto, pese a la "proliferación y promiscuidad metafórica" del concepto del "mapeo" (Craib, "Historical Geographies" 3 ), aluden tanto a sus significados literales como simbólicos. Porque, como nos recuerda Denis Cosgrove, cualquier reflexión que incluya un "mapeo" supone entender el mapa como un producto determinado culturalmente y como un elemento de la cultura material. Un análisis de la serie Explorers' Maps de Mexico This Month ilumina las complejas formas en que las revistas se involucraron en la estética y geopolítica del turismo durante el período de construcción nacional del México posrevolucionario.

Mexico This Month apareció por primera vez en 1955, en medio del período de acelerado crecimiento económico conocido como el "milagro mexicano". Durante estas décadas, debido a una fuerte inversión en el desarrollo industrial y capitalista, la economía y la sociedad del país sufrieron grandes transformaciones, pasando de tener una base mayoritariamente agrícola a una urbana (la construcción de una carretera de cuatro carriles hacia el sur, uniendo la Ciudad de México y Acapulco, fue una innovación sustancial en este sentido). ${ }^{1}$ Con el giro a la derecha iniciado por el presidente Miguel Alemán, México disfrutó de un prolongado período de estabilidad política (el más largo desde el porfiriato) bajo la apariencia de una "contrarrevolución": a partir de 1940, el compromiso de afrontar las desigualdades en la distribución de la riqueza y la dominación económica extranjera se vio seriamente amenazado, temas que habían estado

1 En la década de los cincuenta, se inauguraron en México una serie de superautopistas, entre ellas, la carretera Panamericana transnacional desde El Paso hasta la frontera con Guatemala. De hecho, "para el año 1957, México contaba con quince mil millas de rutas pavimentadas, testimonio tanto del compromiso del gobierno con la construcción de carreteras, como de la tecnología de los nuevos equipos de pavimentación importados desde Estados Unidos” (Sherman 547).

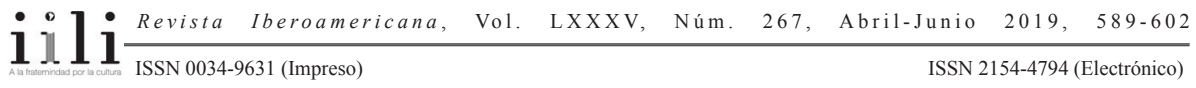


en el corazón de la Revolución Mexicana. ${ }^{2}$ Además, durante el período de posguerra, México pasó por una fase de creciente cordialidad en sus relaciones internacionales con Estados Unidos, transformándose en "una vía de salida fundamental para el capital estadounidense y en un aliado confiable durante la Guerra Fría que ya se encontraba en marcha" (Zolov 250). En efecto, la rápida industrialización de México se vio beneficiada considerablemente por capitales estadounidenses, préstamos e intereses empresariales, tanto así que, como ha señalado Héctor Aguilar Camín, "para los años sesenta la dependencia mexicana en el capital y la tecnología extranjera se había vuelto, al igual que en el porfiriato, bastante evidente" (Aguilar 162). A medida que la clase gobernante mexicana se volvía más y más conservadora durante esos años, también se volvía más abiertamente nacionalista. ${ }^{3}$ La inversión en el turismo fue una parte significativa de este proceso, así como un indicador de una nueva fortaleza del país. Si bien, como ha señalado Berger, el nacionalismo revolucionario debió haber sido ideológicamente contrario al turismo, este permitió que México participara del capitalismo y fue, por lo tanto, fundamental para la recuperación económica y la estabilidad política del país durante los años cuarenta y cincuenta. De hecho, una de las muchas paradojas de México es "el hecho insólito de que un movimiento revolucionario que experimentó con modos de producción colectivistas e incluso socialistas, condujera a un régimen capitalista tan profundamente injusto" (Gillingham y Smith 2). ${ }^{4}$ El turismo no solo se convirtió en un medio para que la nación superara los severos problemas financiaros derivados de su prolongado conflicto interno y de la Gran Depresión. Como industria que celebraba lo propiamente mexicano y que, por lo tanto, debía estar dirigida y administrada por mexicanos, el turismo fue considerado por las élites del país como compatible con los objetivos de la Revolución y como un medio para transformarse en un país "moderno". 5

Durante esta Edad de Oro, un grupo autoproclamado de empresarios, llamado el Comiténorteamericano pro-México, lanzó Mexico This Month, bajo la dirección editorial de Anita Brenner. ${ }^{6}$ Este grupo de ejecutivos norteamericanos, banqueros y antiguos

2 De hecho, para el momento en que Alemán, considerado ampliamente como el "padre" de la industria turística mexicana, dejó la presidencia en 1952 para asumir un cargo en la sucesión del Departamento de Turismo, "la 'revolución institucionalizada' no era más que un nombre" (Sherman 539).

3 Como ha observado Zolov, una paradoja simultánea surgió en las relaciones geopolíticas: La más amplia reivindicación de nacionalismo en México, de la que el turismo formaba parte, "generó diversos impedimentos a la plena materialización de las metas de los Estados Unidos - económicas, diplomáticas y militares- tanto en el país como a nivel regional" (259).

4 El libro de Gillingham and Smith reexamina las complejidades del período revolucionario mexicano, revaluando tradicionales opiniones sobre una "pax priísta [que] no es congruente" (1).

5 Ver Berger, The Development of Mexico's Tourism Industry: Pyramids by Day, Martinis by Night.

6 Brenner había escrito anteriormente dos reconocidos y ahora canónicos libros sobre arte e historia mexicana: Idols behind Altars (1929) y The Wind that Swept Mexico (1943), gracias a los cuales, junto con su profunda relación y promoción de las obras de las más importantes figuras del llamado

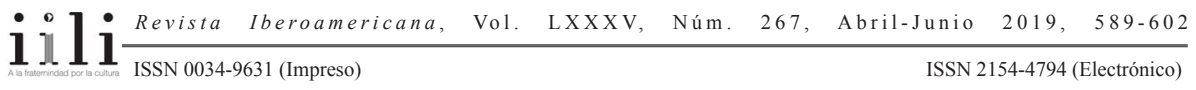


residentes de Ciudad de México se formó en junio de 1954 tras la devaluación del peso producida ese año y con el propósito explícito de "fomentar las buenas relaciones entre México y los EEUU de Norteamérica mediante actividades culturales, cívicas y publicitarias". ${ }^{7}$ El grupo contó con el patrocinio y el apoyo oficial del Estado mexicano, el entonces ministro de Hacienda, Gilberto Loyo, y el presidente Adolfo Ruiz Cortínez. Sus esfuerzos, bajo la dirección de John McIntyre (de General Motors) y del banquero William Richardson, estuvieron claramente motivados tanto por intereses supuestamente "filantrópicos" como por intereses comerciales, ya que General Motors y el National City Bank de Nueva York eran avisadores regulares en la revista. ${ }^{8}$ La revista, por lo tanto, fue concebida como un medio para mejorar las relaciones sociales y comerciales entre México y Estados Unidos, a través de la promoción de los viajes, la inversión y la jubilación en territorio mexicano. Brenner articuló su agenda y su participación en términos culturales: en tanto viajera que a lo largo de su carrera había "promovido el viaje" a través del periodismo y de las guías turísticas, insistió en la necesidad de este medio para proyectar a los vecinos del norte una imagen más desarrollada de México (Monsiváis xvii). De hecho, una revista de viajes de esta naturaleza, argumentó, era "cosa de cajón en todo país moderno". Así, Mexico This Month fue concebida como respuesta a una crisis tanto geopolítica como económica. Su objetivo era intervenir en y fomentar un mercado turístico irregular durante las décadas de posguerra y, al hacerlo, promover los intereses comerciales al norte y al sur de la frontera. En este sentido, sin duda formó parte de lo que Ricardo Salvatore, siguiendo a Stephen Greenblatt, denomina la maquinaria representacional del imperio informal, donde los negocios y el conocimiento se encuentran interconectados. ${ }^{9} \mathrm{Al}$ mismo tiempo, la revista se convirtió en una herramienta para contrarrestar lo que Brenner describió como una imperante "desconfianza hacia México" y una "prensa hostil" en el norte, donde México y otros países latinoamericanos habían sido catalogados durante largos años como moralmente decadentes, políticamente inestables y económica y racialmente atrasados.$^{10}$ Mexico This Month anunció sus intenciones en su número inaugural, bajo la firma "Operación Amigos":

Renacimiento mexicano, se hizo muy conocida. También había publicado una guía de viaje de México, Your Mexican Holiday (1932), que alcanzó cinco ediciones.

"Memorandum", Anita Brenner Papers 96:5.

8 Como apunta Ricardo Salvatore, los móviles de los diversos embajadores del "imperio informal" pueden ser articulados de maneras complejas: "Las motivaciones del imperio informal confrontaron argumentos de interés económico, benevolencia, reforma moral, conocimiento y el 'interés nacional"” (Salvatore 71-72).

9 Ver Salvatore, "The Enterprise of Knowledge".

${ }^{10}$ Para mayor información sobre este tema, ver Anderson, "What's to Be Done with 'Em'?”.

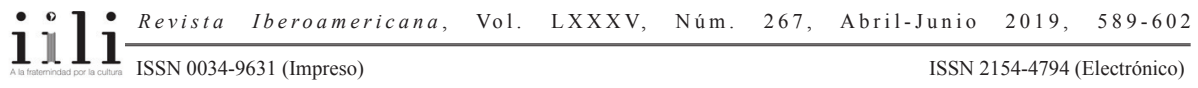


Creemos que una de las mejores formas de crear un mayor entendimiento entre dos pueblos es a través del viaje [...] [y], al traducir México al inglés, estaremos haciendo nuestra labor en la gran tarea de acercamiento hacia la que se dirige América [...] [porque] Hoy en día, la idea de un vecino próspero y contento es un buen negocio y una buena política. (Mexico This Month, 1995, 5)

El fomento del turismo y de la inversión, por lo tanto, fue entendido como un mecanismo de diplomacia suave o informal, una manera de ir "[haciendo] ambiente, para ir desvaneciendo confusiones y agresiones". ${ }^{11}$ En una industria donde "incluso la más mínima señal de peligro puede destruir un destino", el impacto potencial de los esfuerzos de la revista en pos de contrarrestar la imagen negativa de México, de "conducir los dólares hacia el sur y ayudar a disminuir miedos innecesarios o irreales", no puede ser subestimado (Clancy 127). ${ }^{12}$

¿Pero exactamente cómo la revista llevó a cabo esta tarea? Desde su creación, Mexico This Month fue concebida como un proyecto binacional, como "la voz de México en inglés". ${ }^{13}$ Reunió a escritores, artistas emergentes y establecidos, provenientes de México y de Estados Unidos, para promover la historia, geografía y cultura del país. Algunos de los más conocidos fueron Frank Brandenburg, Leonora Carrington, Matías Goeritz, Augusto Monterroso, Juan Rulfo y Leopoldo Zea. En esencia, al enfocarse en sitios de interés turístico, aspectos de la herencia cultural y específicamente indígena de México, así como en la vida política y social, Mexico This Month ofreció una mezcla del tipo de cobertura brindada antes por su predecesora bilingüe, Mexican Folkways, y su homóloga, Mexican Life, con el tono y diseño más popular de revistas de ambos lados de la frontera como Life y Siempre! Estas, como parte de su agenda "moderna", intentaron atraer lectores poniendo un fuerte énfasis en lo visual y dando cobertura a la vida de celebridades. Así, Mexico This Month combinó artículos dedicados a destinos como la capital, las ciudades coloniales y Acapulco, con otros sobre museos, sitios arqueológicos y fiestas, junto a consejos para los viajeros sobre qué llevar y qué ropa usar en cada época del año, y cobertura de, por ejemplo, el fenómeno Kennedy, relativo a la visita de John F. Kennedy al país, en 1962.

El fomento del turismo y la inversión adoptó diversas formas en Mexico This Month. Entre las más explícitas se encontraba una columna regular llamada National Panorama, en la que se informaba a los lectores sobre la situación del mercado de valores, la legislación bancaria del país, o aspectos de la política gubernamental (por ejemplo, comentando un discurso presidencial, o como el caso de una columna, escrita

11 Comité norteamericano pro-México, 21 junio 1954 (Anita Brenner Papers, 16:6).

12 Anita Brenner, "Closing speech to the Congress of Inter-American Studies", University of Florida, December 1955 (Anita Brenner Papers, 16:8).

13 "Memorandum", Anita Brenner Papers 96:5.

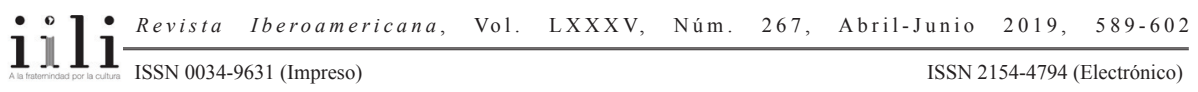


por Loyo, sobre la inversión extranjera en México). El énfasis de la gran mayoría de estos artículos estaba puesto en la estabilidad política del país, su seguridad económica y los beneficios del desarrollo y la industrialización. La inclusión de un mapa desplegable llamado Happy shoppers, o dónde gastar dinero eficientemente en la Ciudad de México, así como una serie especial dedicada a la jubilación (llamada Search for Eden) y artículos regulares sobre la compraventa de propiedades, fueron otras iteraciones de esta agenda. ${ }^{14}$ En esencia, por medio de estos mecanismos, México fue concebido como un gran mercado potencial: un imán para consumidores e inversionistas por igual. Es notable que en el mismo momento en que el país desarrollaba su reputación como paraíso de la alteridad y la aventura para los visitantes bohemios del norte, aquellos viajeros de estadías más extensas, correspondientes a los lectores de Mexico This Month -un público de mayor edad, acaudalado, compuesto por profesionales y empresarios-fueran de particular interés para el Estado. Porque si bien el "milagro" había tenido éxito en aumentar el número de visitantes, para mediados de los años cincuenta el tipo de turista norteamericano atraído por México había comenzado a causar preocupación. Como ha observado Michael Clancy: "Las estadías cortas implicaron gastos relativamente bajos por visita y se intensificó la reputación de las áreas fronterizas como centros de vicio y contrabando" (Clancy 45). Algunos de los mecanismos más sutiles para fomentar un sentido de fraternidad y confianza en el hemisferio, y para transmitir el cambio en la reputación de México de ser el vecino rebelde al buen vecino, incluyeron una página regular de correspondencia de los lectores. Este foro funcionó como una oficina de información-recibiendo preguntas sobre alojamiento, rutas, compra de ciertos bienes de consumo o costos de envío, por ejemplo-y finalmente se formalizó para transformarse en un servicio pagado conocido como The Question Desk. Por otra parte, en la página editorial llamada Person to Person, Brenner se dirigió a los lectores abordando temas de actualidad, interpretando algún aspecto de la cultura mexicana o centrándose en acontecimientos recientes. "El estilo", señaló Brenner, "se ha mantenido casual y de fácil acceso, bajo la premisa de que un tono similar al de una conversación con un conocido o un amigo, es preferible al ruido y la grandilocuencia". ${ }^{15}$

Uno de los aspectos más llamativos del repertorio visual de Mexico This Month durante sus primeros años fue una serie de mapas desplegables y hechos a mano de México, su capital y otros destinos turísticos populares como Veracruz y Acapulco. Creados por uno de los artistas del equipo, Vladimir Machados (seudónimo de un artista e inmigrante ruso entonces residente en la capital, e hijo del novelista Victor Serge), estos coloridos Explorers' Maps condensaron diversos aspectos del discurso turístico dominante, que concebía a México como una encarnación de la modernidad

\footnotetext{
14 Ver, respectivamente los números de agosto de 1956, agosto de 1963 y diciembre de 1956.

15 "Memo on Tourist Travel" (Anita Brenner Papers, 108:5).
}

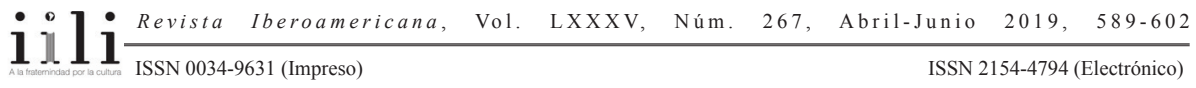


y la antigüedad. Durante la década de los veinte y treinta, las campañas publicitarias se habían dirigido a los viajeros internacionales destacando los recursos naturales del país, sus pueblos indígenas, sus costumbres regionales y su arte popular, así como la proximidad de México y Estados Unidos a través del ferrocarril. Sin embargo, desde la década de los cuarenta, como ha notado Saragoza, cuando Alemán realizó esfuerzos conscientes para modernizar el turismo mexicano, separándolo de su dependencia en lo folclórico y cultivando así una visión más metropolitana, "Los turistas, deseosos de experimentar la 'cultura mexicana', se encontraron con una infraestructura que la hacía posible, disponibilidad inmediata y con lo exóticamente diferente" (Saragoza 108). Así, además de promover la seguridad y la estabilidad del país a través de los mecanismos ya descritos, la serie Explorers'Map-incluyendo una amplia gama de planos de ciudades, estados, carreteras, puertos y zonas de pesca- subrayó la accesibilidad y navegabilidad del país. Hasta cierto punto, estas imágenes cartográficas cumplieron el rol de aquellas que se encuentran en narrativas de viajes convencionales o guías turísticas: proporcionar una carta de navegación de un destino o, digamos, un panorama general de la geografía de la nación, así como orientar y permitir a los lectores recorrer rutas hacia, en, y entre distintos lugares. En contraste con la "seudo-objetividad" de los simples "mapas científicos", los mapas desplegables de Mexico This Month eran pictóricos y altamente estilizados, por lo que a menudo desmentían la claridad y neutralidad de sus homólogos más sobrios. Más bien, estos mapas visualizaron y consolidaron la diversidad y la historia de México de maneras complejas e incluso contradictorias.

El "Wayward Wanderers' Map of Oaxaca", por ejemplo, representa a los diversos habitantes indígenas del Estado (incluyendo a los Tejuana y los Mixteca) en un paisaje poblado por catorce figuras humanas, todas ellas vestidas con trajes tradicionales, "para aquellos que deseen experimentar lo nativo", en palabras de la leyenda del mapa. Este mapa proporciona una visión general de las figuras indígenas ubicadas en distintos puntos del Estado, todas ellas desprovistas de rasgos faciales e identificadas únicamente por medio de sus vestimentas (para las cuales también se ofrece un número que las identifica), lo que implica que son vistas ya no como individuos sino como "tipos", cuyas identidades son fácilmente asimilables. En contraste, un boceto del Monte Albán, en la esquina superior derecha del mapa, proporciona lo que podría ser una visión a ras de suelo de esas "refinadas viejas ruinas". En conjunto, la visión panorámica y el primer plano, construyen "perspectivas irrealizables y paisajes imposibles, donde características geográficas dispares [están] reunidas e intencionalmente ordenadas dentro de un mismo cuadro" (Craib, "Historical Geographies" 154). Si bien el lector es explícitamente invitado a conocer Oaxaca "desde una posición elevada... Apolínea", en el mapa hay pocas posibilidades de "explorar el territorio, ya que no hay 'espacio' por el cual deambular” (Padrón 60-61). A pesar de la imagen pictórica de un tren y de los rieles que atraviesan el Estado, el plano enfatiza su separatismo y anacronismo: contenido/constreñido por una frontera gruesa, en negrita, de color rojo y blanco, más

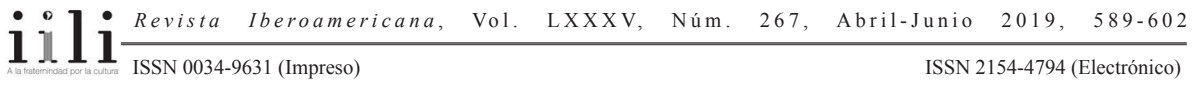


allá de la cual las carreteras y vías del tren desaparecen, pues el espacio que sigue está en blanco, Oaxaca es representada como un lugar fuera de la modernidad; fuera de la nación, incluso. Más aún, sus pueblos antiguos continúan siendo antiguos, atados ineludiblemente a las ruinas de un sitio precolombino. En algún nivel, desde luego, por más que ilustre e instruya a los lectores menos informados acerca de las diferencias raciales del país, una imagen como ésta claramente vuelve a apelar a la antigua diversidad racial de México como fuente y recurso a ser explotado. Del mismo modo, la repetición de una figura imperial en la serie de mapas de la revista-ya sea invocada en la narrativa o de manera gráfica (como fue el caso de las imágenes que acompañaban a la serie Search for Eden sobre jubilación, que solía incluir a un conquistador español sosteniendo palos de golf) implicó que el México moderno todavía estaba a tiempo para la exploración, explotación y extracción.

De hecho, Mexico This Month proporcionó a sus lectores un medio concreto para satisfacer estos impulsos. Tras su gran aceptación y éxito, los Explorers' Maps fueron comercializados y vendidos por separado de la revista, como productos artesanales y "folclóricos". Esta función independiente y accesoria, pone en evidencia el potencial del mapa en tanto mercancía y, por ende, demuestra también las operaciones más amplias, propias del capitalismo moderno, a las que Mexico This Month apostaba y que intentaba promover. Aunque en este formato los mapas fueron vendidos como folletos plegables portátiles, en algunos casos su utilidad como herramienta de orientación es discutible (un tema al que volveré más adelante); lo que sí está documentado en las páginas de los lectores y en la sección editorial, son los elogios a su valor estético o suvenir en tanto objeto. No obstante, esta iniciativa pone en evidencia un problema de "marca" vinculado a la revista y a la propia nación, elemento que también estaba en juego en la serie Explorers' Map. Tanto en su versión desplegable como en su formato portátil, los mapas estuvieron ligados a los primeros esfuerzos de la revista por alcanzar diversificación comercial, reconocimiento de su nombre y lealtad. Sin embargo, si "en-marcar" constituye un gesto territorializador, como nos recuerda Cosgrove, el reiterado énfasis de los mapas en representar a México como una unidad política singular, además de establecer una intertextualidad discursiva dentro y fuera de la serie, insinuó también una retórica nacionalista. ${ }^{16}$ Es decir, la repetición visual y la insistencia en la geografía humana, cultural y política de México durante este período, resonó con los esfuerzos a nivel nacional por afirmar la identidad del país como una República moderna. Como observa Ricardo Padrón, "la forma de construcción colectiva que conocemos como Estado-Nación [...] es inseparable de la imagen clara de un territorio que inspira nuestro afecto, exige nuestra lealtad, nos convoca a nuestro hogar" (9, traducción mía). En efecto, el poder icónico de los contornos de la nación

16 Ver Cosgrove, "Introduction: Mapping Meaning”.

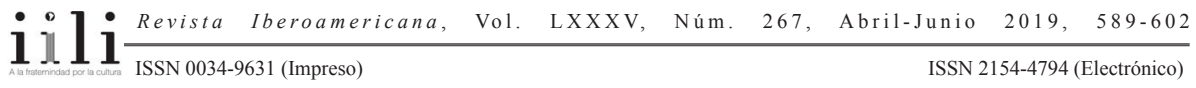


no pasó desapercibido para los avisadores de la revista. Kodak utilizó la imagen de una película de fotos con la forma reconocible de la geografía mexicana, asegurando a los lectores que 'It's the same word in Mexico'! ${ }^{17}$

Si bien los mapas de Mexico This Month trataban sobre identidad, capacidad de recaudación y ganancia, su estética también evidenciaba un lenguaje visual equívoco, mezclando no sólo lo geográfico con lo temático, sino también lo narrativo con lo gráfico, los artefactos modernos con los pre-modernos. En los Explorers' Maps del Paseo de la Reforma y de Chapultepec, por ejemplo, que retratan una de las principales avenidas y parques de la Ciudad de México, respectivamente, los edificios clave, sitios y monumentos -como el Bellas Artes, la Torre Latinoamericana y el Ángel de la Independencia-son destacados en los itinerarios por medio de grandes distorsiones en la perspectiva y el uso de colores intensos (rojo y blanco contra un fondo negro y envolvente, en el primer mapa, azul, gris y blanco, en el segundo). Como resultado, ambos mapas tienen la apariencia de caricaturas, por lo que es probable que hayan adquirido valor turístico como los artículos de colección en que se transformaron después de su publicación. Aún así, la indiscutible naturaleza excesiva de ambos mapas -también presente de diversas maneras en varios otros de la serie- es también relevante, podría decirse, a nivel fenomenológico. Como forma, el mapa normalmente depende de su accesibilidad y contención; de fomentar un recorrido sencillo del espacio. La distorsión en las proporciones de los mapas del Paseo de la Reforma y de Chapultepec, sin embargo, enfatizan la densidad y la verticalidad, e inevitablemente apartan la mirada del turista del nivel del suelo y de la planta cuadriculada de la ciudad, para poner su atención en la enrevesada negociación entre la ruta/sitio y el carácter vertiginoso del espacio urbano. Si la tradicional promesa de accesibilidad propia de la cartografía fue subsumida por la subjetividad de los Explorers' Maps (que también cuestionaron su utilidad como objetos materiales), la expresión y promoción de la modernidad mexicana por parte de la revista, a la que ya me he referido antes, fue a su vez socavada por la estética particular de esta serie. En términos de composición, los mapas desplegables utilizaron en muchas ocasiones cartelas, junto a otros signos y símbolos cartográficos que evocaban el lenguaje visual y el modo de trazar mapas propios de la colonia y de la etapa pre-moderna. En este sentido, la figura imperial presente en la serie Search of Eden recuerda a los sujetos que describían los viajes en los primeros mapas, indicando las operaciones militares y comerciales que luego hicieron posible el trazado de los planos geográficos como tales (en este caso, con un atuendo de golfista que alude al sustento imperialista propio del viaje de placer moderno) (Certeau 121). Esta figura aparece también en "The Trail of Cortés: A Map of Intrepid Explorers", que invita a los

\footnotetext{
17 Para mayor información sobre cómo los avisadores estadounidenses aprovecharon el nacionalismo mexicano durante y después de la Segunda Guerra Mundial, ver Moreno, Yankee Don't Go Home! Mexican Nationalism.
}

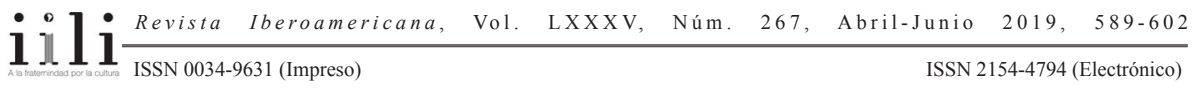


lectores a re-trazar la incursión original desde Veracruz a Tenochtitlán, atravesando varios campos de batalla importantes. También resulta reveladora la asimetría de escala entre la gran figura pictórica de un conquistador español con su armadura y otros símbolos que dominan la ruta y el catálogo (una colección de cráneos, un templo precolombino), y los indescifrables planos urbanísticos de Veracruz y Tenochtitlán que enmarcan el principio y el final del sendero. Este mapa, en realidad, no trata sobre cómo sortear esa ruta, sino más bien sobre la historia que le ha dado forma. En consecuencia, además de la "fantasía de capital" sostenida por la revista a través de los diversos medios antes descritos, estos mapas también perpetuaron, hasta cierto punto, la continua fantasía de conquista prometida para quien viajara a México. ${ }^{18}$

Tal vez la representación más clara del país en tanto "espacio anacrónico" (McClintock 40) sea el "Complete Explorers' Map for Treasure Hunters on Land and Sea" (Fig. 1), que indica los botines disponible en varios lugares a lo largo de México

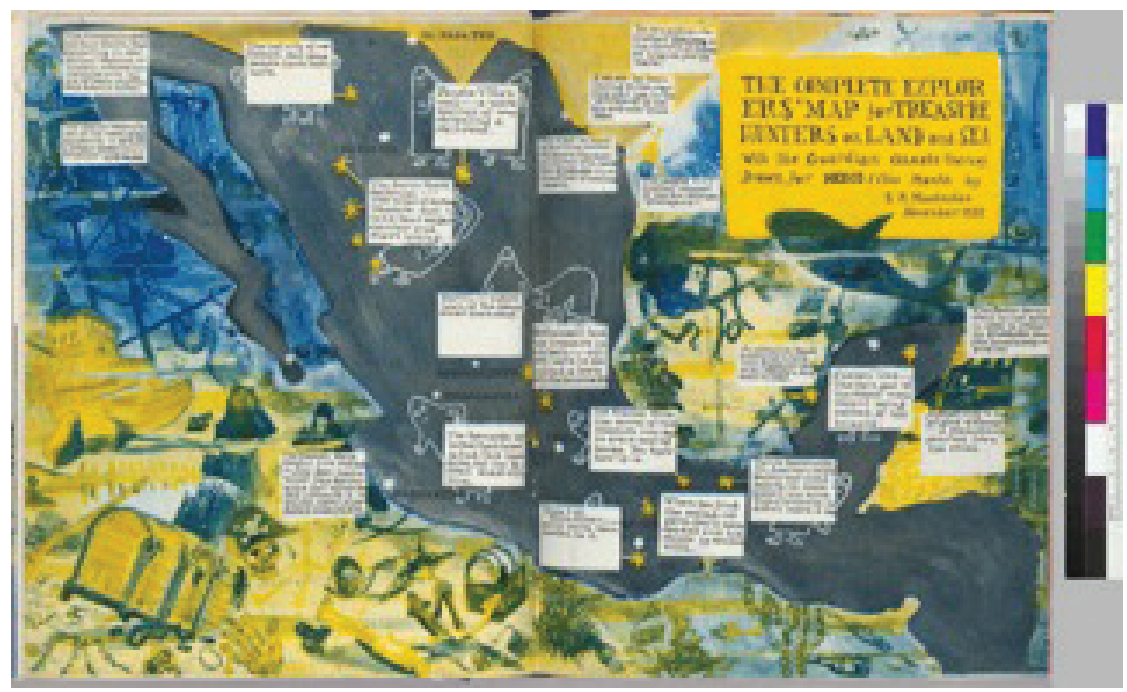

Figura 1

y de las aguas pesqueras que lo rodean. Aquí, la fantasía de capital y la fantasía de conquista se fusionan. Al igual que el caso de "The Trail of Cortés", el mapa "Treasure Hunters" representa una tierra acechada por su historia colonial: las únicas figuras que pueblan el territorio son los "Fantasmas de la Guarda", que espían descaradamente desde atrás de los bloques de texto distribuidos en distintos lugares, mientras los

$\overline{21}$ He tomado prestada esta útil frase de James Martin, de su artículo "Mapping an Empire” (2011).

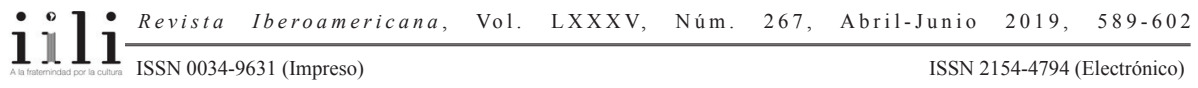


espacios en blanco que ocupan el resto del territorio enuncian lo que Simon Ryan ha denominado "un estado de disponibilidad económica y demográfica" (Ryan 126-27). En efecto, que en esta imagen acuática el país parezca estar casi totalmente sumergido (enclavado en el fondo de un mar amarillento) parecería reforzar al menos uno de los aspectos del persistente mito de México como una "Atlántida morena" (Tenorio Trillo 20). Sin embargo, el texto explicativo contenido en las etiquetas narrativas se caracteriza por una extemporaneidad fundamental, una "ironía posturística" evidente en distintos momentos en otras secciones de la revista: la etiqueta de uno de los sitios arqueológicos precolombinos más visitados de México, dice: “Tumba 7 en Monte Albán - sentimos que haya llegado tan tarde". Así, más que constituir lo que Michel de Certeau siniestramente denomina "procedimientos para el olvido" (Certeau 97), los mapas de Mexico This Month, si bien insisten, sin duda, en la continuidad del potencial de México como frontera colonial, también subrayan la importancia de la historia y de la memoria en la experiencia del viaje. En este sentido, funcionan de manera similar a los mapas que Owen Dwyer, refiriéndose a la obra de Pierre Nora, denomina textos conmemorativos, "en los que la base de una determinada interpretación es infinitamente diferida a otros textos", siendo el resultado "la constitución mutua de texto y contexto" (Dwyer 33). Al registrar de esta manera los mecanismos originales y subsecuentes de conquista, los Explorers' Maps interpelan al 'posturista' que "sabe que el turismo consiste en una serie de juegos entre múltiples textos, y ninguna experiencia singular, auténtica" (Urry 91); y, al hacerlo, apuntan hacia una reactivación lúdica de la función "pre-moderna" del mapa como libro de historia. Así, los mapas de Mexico This Month articulan una compleja epistemología sobre la propia experiencia del viaje y de la industria que la revista promovió y a la que estaba dedicada. De manera similar a los proyectos Situacionistas alemanes, la serie Explorers' Maps invoca y simultáneamente despoja al mapeo de "la acción colonizadora de vigilancia y control" para así desestabilizar sus propios orígenes autoritarios y territorializadores. Como tal, cristaliza la paradoja central identificada por Raymond Craib en su excelente estudio sobre la cartografía de México. Los Explorers’ Maps visualizan la tensión entre la anhelada consolidación del espacio (en la propia elaboración del mapa) y lo que Craib denomina el carácter 'fugaz' del paisaje, "lugares creados y recreados por medio del prisma de la memoria [...] en lugar del lente de la instrumentación” (Cartographic Mexico 12).

Los mapas, según ha señalado Jeremy Black, son similares a las caricaturas. Los Explorers' Maps de Mexico This Month se basan en la distorsión y la exageración que dan vida a la caricatura, pero lo hacen, como he argumentado, de maneras ambivalentes. Una consecuencia evidente de esto es un efecto lúdico, aunque, como fue el caso de otras secciones de la revista, la ironía posturística de la serie podría ser malinterpretada. En un número posterior de la revista, un artículo sobre arqueología que, al igual que el "Treasure Hunters' Map", también ofrecía a los lectores consejos graciosos sobre cómo encontrar los tesoros escondidos de México, provocó un reclamo

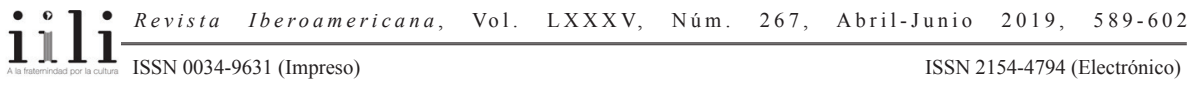


del entonces director del Museo Nacional de Antropología. Ignacio Bernal observó que "nuestras leyes no permiten excavaciones a menos que la excavación sea emprendida por un arqueólogo profesional afiliado a una institución responsable. Cualquiera que tome las sugerencias [del artículo] con seriedad puede terminar en la cárcel". ${ }^{19}$ Sin embargo, y en contra de lo que Bernal pudo haber pensado, Mexico This month fue, en muchos sentidos y como buena parte de los medios impresos de su época, a menudo típicamente oficialista, con abundante material en sus ediciones en apoyo de la descripción de John Mraz sobre las revistas ilustradas contemporáneas de México como eminentemente presidencialistas en tono y perspectiva (Mraz 173). Considerando las circunstancias de su lanzamiento, sus objetivos "diplomáticos" y sus generosos convenios de financiamiento estatal, esto tal vez no sea ninguna sorpresa. ${ }^{20}$ De mayor interés es otra consecuencia derivada de la afinidad cartográfica discutida aquí entre el mapa y la caricatura, que articula una compleja posición respecto de la industria en la que estaba involucrada Mexico This Month: es decir, que la fusión estética entre las imágenes turísticas y coloniales puede, de hecho, servir a propósitos opuestos. En este sentido, los Explorers' Maps cristalizaron una importante ambivalencia, presente a lo largo de sus diecisiete años de vida, en el compromiso de Mexico This Month con el turismo, y que posiblemente reflejó la ambivalencia del propio país. Dicha tensión residía en sus intentos por publicitar el desarrollo y la modernidad del país a través de su diversidad y su historia, y la promoción de un destino de vacaciones a ser consumido por visitantes estadounidenses en busca de un respiro de los propios procesos modernizadores que estaban siendo adoptados entonces en México. Dicha ambivalencia, sin embargo, residía también, fundamentalmente, en cómo reconciliar un deseo de soberanía nacional con las exigencias geopolíticas y de mercado.

Traducido por Alia Trabucco Zerán

BiBLIOGRAFÍA

Aguilar Camín, Héctor y Lorenzo Meyer. In the Shadow of the Mexican Revolution: Contemporary Mexican History 1910-1989. Luis Alberto Fierro, trad. Austin: U of Texas P, 1993.

Anderson, Mark C. “'What's to Be Done with 'Em?': Images of Mexican Cultural Backwardness, Racial Limitations, and Moral Decrepitude in the United States Press, 1913-1915". Mexican Studies/Estudios Mexicanos 14/1 (1998): 23-70.

\footnotetext{
${ }^{19}$ Ignacio Bernal a Anita Brenner, 9 de septiembre de 1965 (Anita Brenner Papers, 83:1).

${ }^{20}$ La seguridad financiera de Mexico This Month estaba cubierta gracias a un importante subsidio estatal, dividido entre el Banco Nacional de México y la Nacional Financiera, lo que garantizó que la mayoría de su ingreso proviniera de una "circulación controlada" al por mayor.
}

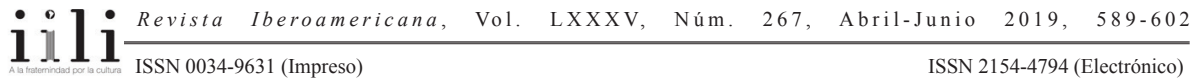


Anita Brenner Papers. Harry Ransom Center, University of Austin, Texas.

Berger, Dina. The Development of Mexico's Tourism Industry: Pyramids by Day, Martinis by Night. Nueva York: Palgrave Macmillan, 2006.

y Andrew G. Wood. Holiday in Mexico: Critical Reflections on Tourism and Tourist Encounters. Durham: Duke UP, 2010.

Certeau, Michel de. The Practice of Everyday Life. Berkeley: U of California P, 1984. Clancy, Michael.Exporting Paradise: Tourism and Development in Mexico.Amsterdam: Pergamon, 2001.

Corner, James. "The Agency of Mapping: Speculation, Critique and Invention." Mappings. Denis Cosgrove, ed. Londres: Reaktion, 1999. 213-54.

Cosgrove, Denis. "Introduction: Mapping Meaning”. Mappings. Denis Cosgrove, ed. Londres: Reaktion, 1999. 1-23.

Craib, Raymond. Cartographic Mexico: A History of State Fixations and Fugitive Landscapes. Durham: Duke UP, 2004.

"Historical Geographies." Mapping Latin America: A Cartographic Reader. Jordana Dym y Karl Offen, eds. Chicago: U of Chicago P, 2011. 153-58.

Dwyer, Owen J. "Memory on the Margins: Alabama's Civil Rights Journey as a Memorial Text.” Mapping Tourism. Stephen P. Hanna y Vincent J del Casino Jr, eds. Minneapolis: U of Minnesota P, 2003. 28-50.

Gillingham, Paul y Benjamin T. Smith eds., Dictablanda: Politics, Work, and Culture in Mexico, 1938-1968. Durham: Duke UP, 2014.

Glusker, Susannah Joel. Anita Brenner: A Mind of Her Own. Austin: U of Texas P,1998. Avant Garde Art and Artists in Mexico: Anita Brenner's Journals of the Roaring 20s. Austin: U of Texas P, 2010.

Hanna, Stephen P. y Vincent J del Casino Jr. eds. Mapping Tourism. Minneapolis: U of Minnesota P, 2003.

Harley, J.B. "Deconstructing the Map". Human Geography: An Essential Anthology. John Agnew, David N. Livingstone y Alisdair Rogers, eds. Oxford: Blackwell, 1996. 422-43.

Martin, James. "Mapping an Empire: Tourist Cartographies of the Caribbean in the Early $20^{\text {th }}$ Century." Early Popular Visual Culture 9/1 (2011): 1-14.

McClintock, Anne. Imperial Leather: Race, Gender and Sexuality in the Colonial Contest. Nueva York: Routledge, 1995.

Monsiváis, Carlos. Introduction. Avant Garde Art and Artists in Mexico: Anita Brenner's Journals of the Roaring 20s. Susannah Joel Glusker, ed. Austin: U of Texas P, 2010. xi-xxiv.

Moreno, Julio. Yankee Don't Go Home! Mexican Nationalism, American Business Culture and the Shaping of Modern Mexico, 1920-1960. Chapel Hill: U of North Carolina P, 2003.

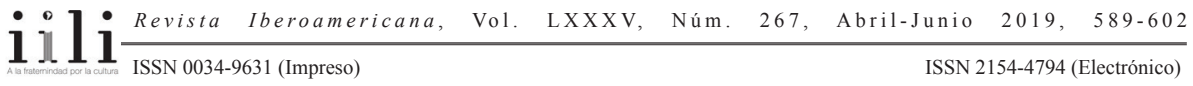


Mraz, John. Looking for Mexico: Modern Visual Culture and National Identity. Durham: Duke UP, 2009.

Padrón, Ricardo. The Spacious Word: Cartography, Literature and Empire. Chicago: U of Chicago P, 2004

Ryan, Simon. "Inscribing the Emptiness: Cartography, Exploration and the Construction of Australia". De-Scribing Empire: Postcolonialism and Textuality. Chris Tiffin y Alan Lawson, eds. Londres: Routledge, 1994. 115-30.

Salvatore, Ricardo. "The Enterprise of Knowledge: Representational Machines of Informal Empire". Close Encounters of Empire: Writing the Cultural History of U.S.-Latin American Relations. Gilbert Joseph, Catherine Le Grand y Ricardo Salvatore, eds. Durham: Duke UP, 1998. 69-104.

Saragoza, Alex. "The Selling of Mexico: Tourism and the State, 1929-1952." Fragments of a Golden Age: The Politics of Culture in Mexico Since 1940. Gilbert Joseph, Anne Rubenstein y Eric Zolov, eds. Durham: Duke UP, 2001. 91-115.

Sherman, John W. "The Mexican 'Miracle' and its Collapse." The Oxford History of Mexico. William Beezley y Michael C. Meyer, eds. Oxford: Oxford UP, 2010. 537-68.

Tenorio Trillo, Mauricio. "El peso de una imagen: México". México ilustrado: libros, revistas y carteles 1920-1950. Salvador Albiñana, ed. Mexico: Editorial RM, 2010. 17-22.

Thompson, Carl. Travel Writing. Oxford: Routledge, 2011.

Urry, John. The Tourist Gaze. Londres: Sage, 2002.

Zolov, Eric. "Between Bohemianism and a Revolutionary Rebirth: Che Guevara in Mexico." Che's Travels: The Making of a Revolutionary in 1950s Latin America. Paulo Drinot, ed. Durham: Duke UP, 2010. 245-82.

Palabras clave: $\quad$ turismo, modernización, Mexico, This Month, mapeo

Recibido: $\quad$ junio 2016

Aprobado: $\quad$ septiembre 2018

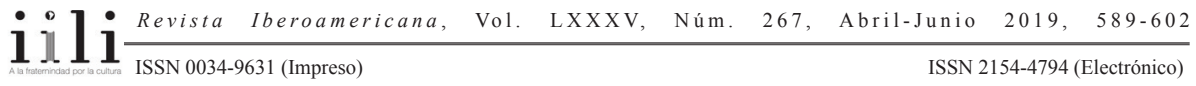

